\title{
Job stress and resilience in Iranian nurses during the COVID-19 pandemic: A case-control study
}

\author{
Gholam-Abbas Shirali ${ }^{\mathrm{a}}$, Arman Amiri ${ }^{\mathrm{b}}$, Khalil Taherzadeh Chananic, Maryam Silavi ${ }^{\mathrm{b}}$, \\ Sanaz Mohipoor ${ }^{\mathrm{b}}$ and Payam Rashnuodi ${ }^{\mathrm{b}, *}$ \\ ${ }^{a}$ Department of Occupational Safety and Health Engineering, Faculty of Health, Ahvaz Jundishapur University \\ of Medical Sciences, Ahvaz, Iran \\ ${ }^{\mathrm{b}}$ Student Research Committee, Ahvaz Jundishapur University of Medical Sciences, Ahvaz, Iran \\ ${ }^{\mathrm{c}}$ Occupational Health Research Center, School of Public Health, Shahid Sadoughi University of Medical \\ Sciences, Yazd, Iran
}

Received 21 March 2021

Accepted 17 September 2021

\begin{abstract}
.
BACKGROUND: The COVID-19 pandemic has created a wide range of sociocultural pressures on nurses. Resilience is defined as one's ability to adapt to an unpredictable situation and it can be a factor in accepting an undesirable psychosocial situation.

OBJECTIVE: The aim of the present study was to examine resilience in nurses in the face of job stress during the COVID-19 pandemic.

METHODS: The study was carried out as a case-control study with participation of 400 nurses as the target group (nurses exposed to COVID-19 patients) and the control group (nurses not exposed to COVID-19 patients). To examine resilience and job stress, Conor and Davidson's questionnaire and OSIPOW questionnaire were used respectively.

RESULTS: The mean scores of job stress and resilience were significantly different between the target and control groups $(p<0.05)$. So that resilience in the target group was less than that in the control group. In addition, job stress in the target group was higher than that of the control group $(p<0.05)$. There was a significant and negative correlation between resilience and job stress and the correlation was stronger in the target group $(p<0.05)$.

CONCLUSIONS: Given the high job stress score in the participants and its negative correlation with resilience, there is need to provide the health personnel with efficient preventive and treatment approaches, improve and educate the principles of resilience, improve mental health services system, and introduce programs to control some of demographical factors in job stress such as physical activity, and employment status of nurses.
\end{abstract}

Keywords: COVID-19, job stress, resilience, nurses, psychophysical health

*Address for correspondence: Payam Rashnuodi, $\quad$ Student Research Committee, Ahvaz Jundishapur University of Medical Sciences, Ahvaz, Iran. E-mail: payaamrashnodi@gmail.com.

\section{Introduction}

Today, job stress is one of the main phenomena of social life and a serious threat to individual's health in the world. According to the International Labour Organization (ILO), job stress is the main health 
threat in individuals [1]. It is estimated that $75 \%$ of medical problems are directly caused by stress; thus, stress is responsible for notably heavy costs of health care services and poor performances [2]. Based on studies conducted in the past few decades, nursing profession is one of the stressful and challenging jobs given its specialized nature, complicacy, and the need for managing emergency situations [3, 4]. Job stress in nurses is a source of concern as to mental health, mental diseases, and disorder in employees' performance. It can have negative effects on nurses' attitudes and behavior [5-7]. Among the factors that might create stress at work environment for nurses are conflicts with patients, interpersonal relationship with physicians and other colleagues, low support for nurses, high job demand, leadership and management style, lack of a rewarding system, rotating work schedule, dealing with emotional needs of patients, overtime work, facing death, and ambiguity of medication results $[8,9]$. In addition, the outbreak of COVID-19 has added to psychophysical problems of medical team members and nurses in particular who are in direct contact with COVID-19 patients [10-12]. COVID-19 is a new member of Coronaviridae, which was found in 2019 in Wuhan, China [13, 14]. COVID19 is a serious global health threat [15] and the biggest atypical pneumonia outbreak since severe acute respiratory syndrome (SARS). A few weeks after the outbreak of COVID-19, the total number of death cases had already exceeded that of SARS [16, 17].

According to the available reports, the first definite case of COVID-19 was found in Iran on $19^{\text {th }}$ February 2020. Ten days after the first COVID-19 caused death, the disease spread from 19 provinces to 31 provinces [18]. This made Iran as one of the main countries afflicted by COVID-19 in the world. Since the initiation of the pandemic, new cases of COVID-19 have been found and reported on daily basis in Iran. Given the high prevalence of the disease, the health system is under extreme physical and mental pressure to provide care to COVID-19 patients [19]. Studies have shown that during epidemics like Influenza, Ebola, and SARA, individuals experienced a wide range of psychosocial effects at personal, social, and international levels. At the personal level and given the high mortality rate caused by such diseases people tend to feel high anxiety, fear, and stress. The public belief that there is no efficient way to prevent or treat COVID-19 has increased the symptoms of mental problems [10, 20,21]. Lack of adequate facial masks and other health equipment to prevent COVID-19 intensifies the negative effects on the mental health in society [20, 22, 23].The negative outcomes of job stress in nurses and other health care experts include mental disorders, poor mental health, alcohol and drugs abuse, absenteeism, delay in appearing at work, job burnout, injuries at work, skeletomuscular disorders, lower performance, concentration and memory disorder, and negative effects on the immunity system [24, 25]. Therefore, based on scientific reasons one may say that stress might lead to hard situations and accidents in nursing profession [2]. Despite all these challenges, one of the factors that enable nurses to adapt to their situation and have a healthy and stable psychological performance is resilience in the face of psychophysical risk factors. Resilient nurses learn how to overcome their problems and develop better frameworks to face the stress of being exposed to demanding work conditions and environments [23, 26, 27]. Resilience tries to find methods to improve one's capability and create processes to have the required flexibility at all levels of changes and under organizational stress [28, 29]. Wood reported that resilience is the ability of a system to carry out adaptive measures in the face of information change, changes in situations, or new forms of events or survival challenges through using previous adaptations, models, or hypotheses [30]. There has been a growing interest to uncover the way resilience affects health care personnel. Studies have shown that resilience is important in terms of health outcomes such as psychophysical health and job performance $[26,31]$. There have been several recommendations to create resilience during nursing programs [32]. In addition, studies have shown that the indices of resilience can affect job stress [26, 32, 33]. Given the introduction, to help health care personnel, and to improve the quality of services to hospital careseekers, the present study is an attempt to examine resilience in nurses in the face of job stress during COVID-19. The authors wish that the results can help developing efficient strategies to control and prevent the risks of job stress during COVID-19. The results can be also used for job stress risk management to improve health level and performance in the personnel.

\section{Materials and methods}

The study was carried out as a case-control study on 400 nurses working in Ahvaz-based educational hospitals. The participants were selected randomly and filled out online questionnaires. Nurses 
exposed to COVID-19 patients constituted the target group $(n=200)$ and nurses not exposed to COVID-19 patients were considered as the control group $(n=200)$. The Ethics Committees of the Ahvaz Jundishapur University of Medical Sciences approved the study (no. IR.AJUMS.REC.1400.281).

\subsection{Data gathering tool}

Data gathering tool was an e-form that was administered using email. The participants were informed about the objectives of study and those interested, filled out the tool. The questionnaire was anonymous and consisted of three parts including demographical information (e.g. age, work experience, gender, physical activity, education level, work contract, marital status, and number of children). The inclusion criteria were good general health condition, at least one year of work experience, no history of chronic and psychological physical disease, and not using a specific drug for a long period of time [34].

\subsubsection{Resilience}

To examine resilience of the participants, ConnerDavidson Resilience Scale (CD-RISC) was used. The questionnaire has been used in several studies. Mohamadian and Khodabakhsh Koulaie obtained Cronbach's alpha of the tool equal to 0.89 and 0.87 respectively [35, 36]. The items of the tool are designed based on Likert's five-point scale (never $=0$, rarely $=1$, sometimes $=2$, most of the time $=3$, and always $=4$ ) and the score range is from 0 to 100 . The higher the score, the higher the resilience in individuals.

\subsubsection{Job stress}

To examine job stress level, Osipow Job Stress Questionnaire was used. The tool measures stressors like role workload, role incompetence, role dyad, role limitation, responsibility, and physical environment. Reliability and validity of the tool were examined by Sharifian et al. [37] and Cronbach's alpha was obtained equal to 0.83 . The items of the tool are scored based on Likert's five-point scale (never $=1$, sometimes $=2$, mostly $=3$, usually $=4$, and most of the time $=5$ ). The score range of the tool is from 60 to 300 so that the higher the score the higher the job stress. In addition, the score range 60-119 is interpreted as low stress, 120-179 as low-moderate stress, $180-239$ as moderate-severe stress, and $240-300$ as severe stress [38].

\subsection{Statistical analysis}

To examine normal distribution of the variables, Kolmogorov-Smirnov (KS) test was used. Data analysis for not-normally distributed data was done using non-parametric tests using Pearson correlation, independent samples $t$-test, one-way ANOVA, Welch, Kruskal-Wallis test, and Mann-Whitney $U$ test in SPSS (v.25) $(P<0.05)$.

\section{Results}

Table 1 lists the demographics of the control and target groups. The mean scores of job stress and resilience were $190.59 \pm 22.56$ and 61.13 .13 respectively. Table 2 lists the mean score of these two scores and the subscales for the two groups. As shown by the results, the mean scores of resilience and job stress are significantly different between the two groups $(p<0.05)$. The elements of resilience are significantly different between the two groups except for Spiritual influences $(P=0.806))$. In addition, the mean scores of all elements of job stress are significantly different between the two groups $(p<0.05)$ (Table 2). Table 3 lists the mean scores of job stress and resilience based on demographical variables. The mean score of job stress in target group is significantly different in terms of gender and employment contract $(p<0.05)$ so that job stress is higher in women than men $(195.14 \pm 23.82$ and $189.95 \pm 12.69)$. In addition, the mean score of job stress in the individual not in contact with COVID-19 patients is significantly different only based on physical activity level $(p=0.001)$ (Table 3). The mean score of job stress is generally higher in individuals without physical activity compared to those who had physical activities $(62.14 \pm 13.99$ and $58 \pm 12.81$ respectively). Physical activity affected the mean score of resilience $(p<0.05)$. In addition, there is a significant different between individual with different education levels in terms of resilience $(p<0.05)$ (Table 3$)$.

The correlation between resilience and job stress and the elements of these two indices was examined. Table 4 lists the results for the groups in this study. As listed, there is a significant, strong, and inverse correlation between resilience and job stress in the target $(-0.888)$ and control $(-0.910)$ groups and the correlation is stronger in the control group. Resilience also has a significant and inverse relationship with all the elements of job stress $(p<0.05)$. In addition, job stress is significantly and inversely correlated with all the elements of resilience $(P<0.05)$. 
Table 1

Frequency and percentage of the demographical variables of the participants

\begin{tabular}{|c|c|c|c|c|}
\hline \multicolumn{2}{|c|}{ Variables } & \multicolumn{3}{|c|}{ Frequency (percent) } \\
\hline & & Total & $\begin{array}{l}\text { No exposure to } \\
\text { COVID-19 }\end{array}$ & $\begin{array}{r}\text { Exposure to } \\
\text { COVID-19 }\end{array}$ \\
\hline & & $400(100 \%)$ & $\frac{200(50 \%)}{10(5)}$ & $200(50 \%)$ \\
\hline \multirow{4}{*}{ Age } & $25>$ & $26(6.5)$ & $10(5)$ & $10(10)$ \\
\hline & $25-30$ & $129(32.25)$ & $61(30.5)$ & $72(36)$ \\
\hline & $30-35$ & $141(35.25)$ & $79(39.5)$ & $52(26)$ \\
\hline & $>35$ & $104(26)$ & $50(25)$ & $56(28)$ \\
\hline \multirow[t]{2}{*}{ Sex } & Male & $71(17.75)$ & $38(19)$ & $31(15.5)$ \\
\hline & Female & $329(82.25)$ & $162(81)$ & $169(84.5)$ \\
\hline \multirow[t]{2}{*}{ Marital status } & Unmarried & $174(43.5)$ & $87(43.5)$ & $87(43.5)$ \\
\hline & Married & $226(56.5)$ & $133(56.5)$ & $113(56.5)$ \\
\hline \multirow[t]{3}{*}{ Education } & High school diploma & $30(7.5)$ & $15(7.5)$ & $15(7.4)$ \\
\hline & Bachelors' degree & $264(66)$ & $121(60.5)$ & $155(77.5)$ \\
\hline & Masters' degree & $106(26.5)$ & $64(32)$ & $35(15.1)$ \\
\hline \multirow{2}{*}{ Has children } & Yes & $137(34.25)$ & $61(30.5)$ & $85(42.5)$ \\
\hline & No & $263(65.75)$ & $139(69.5)$ & $115(57.5)$ \\
\hline \multirow[t]{3}{*}{ Employment status } & Temporary & $107(26.75)$ & $36(18)$ & $91(45.5)$ \\
\hline & Contractual & $186(46.5)$ & $100(50)$ & $78(39)$ \\
\hline & Life time & $107(26.75)$ & $64(32)$ & $31(15.5)$ \\
\hline \multirow[t]{3}{*}{ Work experience } & $<5$ & $164(41)$ & $164(41)$ & $98(49)$ \\
\hline & $5-10$ & $136(34)$ & $136(34)$ & $56(28)$ \\
\hline & $>10$ & $100(25)$ & $100(25)$ & $46(23)$ \\
\hline \multirow[t]{3}{*}{ Physical activity } & Yes & $70(17.5)$ & $70(17.5)$ & $65(32.5)$ \\
\hline & Not now* & $131(32.75)$ & $131(32.75)$ & $72(36)$ \\
\hline & No & $199(49.75)$ & $199(49.75)$ & $63(31.5)$ \\
\hline
\end{tabular}

*I used to exercise, but not anymore.

Table 2

The mean scores of resilience, job stress, and the elements in the two groups

\begin{tabular}{lcccc}
\hline Variables & Mean \pm SD & $\begin{array}{c}\text { Exposure to } \\
\text { COVID-19 }\end{array}$ & $\begin{array}{c}\text { No exposure to } \\
\text { COVID-19 }\end{array}$ & $p_{\text {-value* }}$ \\
\hline Competence $^{1}$ & $19.56 \pm 5.13$ & $18.97 \pm 5.42$ & $20.78 \pm 4.23$ & 0.001 \\
Negative effect $^{2}$ & $15.35 \pm 4.17$ & $14.94 \pm 4.4$ & $16.23 \pm 3.48$ & 0.004 \\
Secure relationships $^{3}$ & $13.29 \pm 2.81$ & $12.96 \pm 2.79$ & $13.99 \pm 2.73$ & 0.002 \\
Control & $7.17 \pm 2.46$ & $6.97 \pm 2.58$ & $7.59 \pm 2.15$ & 0.021 \\
Spiritual influences & $5.65 \pm 1.61$ & $5.64 \pm 1.52$ & $5.69 \pm 1.81$ & 0.806 \\
Resilience scale & $61 \pm 13.13$ & $59.62 \pm 14.02$ & $63.93 \pm 10.48$ & 0.002 \\
Role workload & $32.26 \pm 5.39$ & $32.89 \pm 5.51$ & $30.95 \pm 4.88$ & 0.001 \\
Role incompetence & $31.76 \pm 5.48$ & $32.5 \pm 5.06$ & $30.19 \pm 6$ & $<0.001$ \\
Role dyad & $34.03 \pm 4.65$ & $34.44 \pm 4.49$ & $33.16 \pm 4.86$ & 0.017 \\
Role limitation & $30.8 \pm 5.31$ & $31.24 \pm 5.4$ & $29.89 \pm 5$ & 0.029 \\
Responsibility & $31.58 \pm 5.89$ & $32.26 \pm 5.63$ & $30.15 \pm 6.19$ & 0.002 \\
Physical environment & $30.16 \pm 8.53$ & $30.83 \pm 8.29$ & $28.73 \pm 8.88$ & 0.035 \\
Occupational stress scale & $190.59 \pm 22.56$ & $194.16 \pm 22.21$ & $183.07 \pm 21.52$ & $<0.001$ \\
\hline
\end{tabular}

${ }^{*} P$ value for Independent sample $T$ test, 1 -personal competence, high standards, and tenacity; 2 - trust in one's instincts, tolerating negative effects and strengthening effects of stress; 3 - positive acceptance of change, and secure relationship.

\section{Discussion}

The COVID-19 pandemic poses a serious threat to global health and has created a wide range of psychosocial effects at personal, regional, and international levels. At the personal level, given the high mortality rate of the disease, the virus has caused anxiety, panic, and stress in individuals [10, 20]. Like other countries, Iran has witnessed stress and several psychological outcomes in different social groups following the pandemic [39]. Taking into account the importance of resilience in psychosocial coping, resilience level in nurses in the face of job stress during the COVID-19 pandemic was examined. The results indicated that job stress in the study groups was not at a desirable level, which is consistent with 
Table 3

The mean score of job stress and resilience based on demographical variables in the two groups

\begin{tabular}{|c|c|c|c|c|c|c|c|c|c|c|c|c|c|}
\hline \multicolumn{2}{|c|}{ Variables } & \multicolumn{4}{|c|}{ Exposure to COVID-19 } & \multicolumn{4}{|c|}{ No exposure to COVID-19 } & \multicolumn{4}{|c|}{ Total } \\
\hline & & \multicolumn{2}{|c|}{ Occupational stress } & \multicolumn{2}{|c|}{ Resilience } & \multicolumn{2}{|c|}{ Occupational stress } & \multicolumn{2}{|c|}{ Resilience } & \multicolumn{2}{|c|}{ Occupational stress } & \multicolumn{2}{|c|}{ Resilience } \\
\hline & & Mean \pm SD & $p$-Value & Mean \pm SD & $p$-Value & Mean $\pm \mathrm{SD}$ & $p$-Value & Mean \pm SD & $p$-Value & Mean \pm SD & $p$-Value & Mean $\pm S D$ & $p$-Value \\
\hline \multirow[t]{4}{*}{ Age } & $25>$ & $198.91 \pm 28.84$ & $0.530^{*}$ & $59.73 \pm 10.89$ & $0.223^{*}$ & $188 \pm 18.27$ & $0.620^{*}$ & $62.64 \pm 9.1$ & $0.586^{*}$ & $193.45 \pm 24.21$ & $0.828^{*}$ & $61.18 \pm 9.91$ & $0.270^{*}$ \\
\hline & $25-30$ & $193.54 \pm 24.92$ & & $60.88 \pm 16.09$ & & $186.28 \pm 26.15$ & & $63.54 \pm 13.21$ & & $190.92 \pm 25.49$ & & $61.86 \pm 15.08$ & \\
\hline & $30-35$ & $195.96 \pm 21.54$ & & $57.07 \pm 12.28$ & & $176.36 \pm 22.85$ & & $65.46 \pm 9.45$ & & $191.31 \pm 23.31$ & & $58.95 \pm 12.19$ & \\
\hline & $>35$ & $191.16 \pm 18.23$ & & $62.16 \pm 14.19$ & & $183.37 \pm 12.04$ & & $63.6 \pm 7.75$ & & $188.47 \pm 16.71$ & & $62.66 \pm 12.32$ & \\
\hline \multirow[t]{2}{*}{ Sex } & Male & $189.95 \pm 12.69$ & $0.049^{* *}$ & $59.49 \pm 8.31$ & $0.922^{* *}$ & $178.88 \pm 22.93$ & $0.068^{\ddagger}$ & $68.6 \pm 8.59$ & $0.062^{* *}$ & $186.82 \pm 16.81$ & $0.079^{* *}$ & $61.84 \pm 9.23$ & $0.490^{* *}$ \\
\hline & Female & $195.14 \pm 23.82$ & & $59.65 \pm 15.08$ & & $183.86 \pm 21.29$ & & $63.16 \pm 10.6$ & & $191.41 \pm 23.58$ & & $60.82 \pm 13.83$ & \\
\hline \multirow[t]{2}{*}{ Marital status } & Unmarried & $196.07 \pm 24.71$ & $0.269^{* *}$ & $60.37 \pm 14.76$ & $0.516^{* *}$ & $181.26 \pm 22.69$ & $0.443^{* *}$ & $63.66 \pm 11.47$ & $0.811^{* *}$ & $191.3 \pm 24.99$ & $0.607^{* *}$ & $61.44 \pm 13.82$ & $0.634^{* *}$ \\
\hline & Married & $192.73 \pm 20.36$ & & $59.12 \pm 13.68$ & & $184.48 \pm 20.66$ & & $64.15 \pm 9.71$ & & $190.01 \pm 20.77$ & & $60.74 \pm 12.73$ & \\
\hline \multirow[t]{3}{*}{ Education } & High school diploma & $194.12 \pm 19.31$ & $0.077^{*}$ & $59.35 \pm 16.23$ & $0.034^{*}$ & $187.75 \pm 24.86$ & $0.313^{*}$ & $58.13 \pm 12.55$ & $0.179^{*}$ & $192.08 \pm 20.93$ & $0.809^{*}$ & $58.96 \pm 14.9$ & $0.555^{*}$ \\
\hline & Bachelors' degree & $196.09 \pm 21.39$ & & $58.22 \pm 14.67$ & & $180.05 \pm 15.76$ & & $65.83 \pm 7.68$ & & $190 \pm 20.91$ & & $61.07 \pm 13.03$ & \\
\hline & Masters' degree & $190.53 \pm 24.11$ & & $62.39 \pm 11.79$ & & $196.63 \pm 37.19$ & & $57.13 \pm 16.99$ & & $191.63 \pm 26.78$ & & $61.43 \pm 12.95$ & \\
\hline \multirow[t]{2}{*}{ Has children } & Yes & $194.03 \pm 19.46$ & $0.954^{* *}$ & $58.7 \pm 13.57$ & $0.511^{* *}$ & $181.54 \pm 17.62$ & $0.527^{* *}$ & $65.82 \pm 8.79$ & $0.104^{* *}$ & $189.03 \pm 19.65$ & $0.335^{* *}$ & $61.47 \pm 12.39$ & $0.643^{* *}$ \\
\hline & No & $194.22 \pm 23.37$ & & $60.03 \pm 14.24$ & & $184.21 \pm 24.09$ & & $62.6 \pm 11.41$ & & $191.4 \pm 23.95$ & & $60.76 \pm 13.52$ & \\
\hline \multirow[t]{3}{*}{ Employment status } & Temporary & $204.29 \pm 27.55$ & $0.027^{\dagger}$ & $55.67 \pm 15.14$ & $0.157^{\dagger}$ & $182.67 \pm 23.92$ & $0.541^{*}$ & $65.21 \pm 10.13$ & $0.472^{\dagger}$ & $192.52 \pm 27.69$ & $0.626^{\dagger}$ & $60.88 \pm 13.45$ & $0.990^{\dagger}$ \\
\hline & Contractual & $192.74 \pm 18.19$ & & $59.92 \pm 13.86$ & & $181.36 \pm 15.34$ & & $63.86 \pm 8.63$ & & $189.67 \pm 18.14$ & & $60.98 \pm 12.76$ & \\
\hline & Life-time & $190.64 \pm 23.26$ & & $61.29 \pm 13.42$ & & $188.47 \pm 27.18$ & & $60.59 \pm 14.76$ & & $190.22 \pm 23.91$ & & $61.16 \pm 13.6$ & \\
\hline \multirow{3}{*}{ Work experience } & $1-5$ & $195.27 \pm 24.69$ & $0.087^{\dagger}$ & $59.83 \pm 15.5$ & $0.592^{\dagger}$ & $185.3 \pm 25.07$ & $0.615^{*}$ & $64.59 \pm 11.78$ & $0.641^{*}$ & $191.42 \pm 25.22$ & $0.061^{\dagger}$ & $61.65 \pm 14.33$ & $0.467^{\dagger}$ \\
\hline & $5-10$ & $190.4 \pm 19.97$ & & $60.5 \pm 11.86$ & & $177.97 \pm 20.28$ & & $63.77 \pm 10.07$ & & $187.13 \pm 20.7$ & & $61.36 \pm 11.46$ & \\
\hline & $>10$ & $197.92 \pm 21.04$ & & $58.08 \pm 14.79$ & & $184.48 \pm 12.68$ & & $62.8 \pm 8.13$ & & $193.92 \pm 19.85$ & & $59.49 \pm 13.29$ & \\
\hline \multirow{3}{*}{ Physical activity } & Yes & $184.25 \pm 9.47$ & $0.142^{*}$ & $64.46 \pm 9.81$ & $0.035^{*}$ & $173.09 \pm 15.34$ & $0.001^{\dagger}$ & $69.2 \pm 5.89$ & $<0.001^{\dagger}$ & $177.63 \pm 14.28$ & $<0.001^{\dagger}$ & $67.27 \pm 8$ & $<0.001^{\dagger}$ \\
\hline & Now not ${ }^{\mathrm{a}}$ & $193.08 \pm 19.14$ & & $61.52 \pm 16.03$ & & $184.85 \pm 18.47$ & & $63.32 \pm 8.93$ & & $190.16 \pm 19.23$ & & $62.14 \pm 13.99$ & \\
\hline & No & $196.39 \pm 24.64$ & & $57.67 \pm 12.74$ & & $191.32 \pm 26.21$ & & $59.18 \pm 13.17$ & & $195.3 \pm 24.99$ & & $58 \pm 12.81$ & \\
\hline
\end{tabular}

a. I used to exercise, but not anymore; $p$-value for ${ }^{*}$ Kruskal-Wallis test; ${ }^{* *}$ Independent Samples Test; ${ }^{\dagger}$ One-way ANOVA; ${ }^{\ddagger}$ Mann-Whitney U test. 


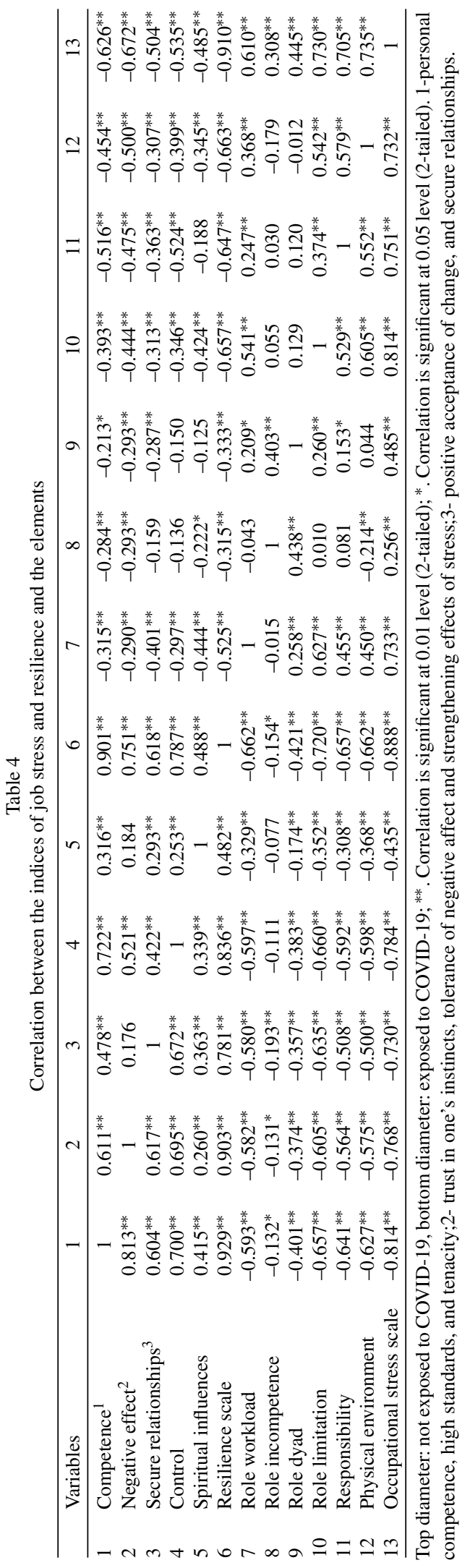

similar studies [40, 41]. Several studies have reported that nursing profession is featured with several challenges such as conflict with patients, interpersonal relationships with physicians and colleagues, poor support for nurses at work, highly demanding job, increase in complicacy of services, decrease in control, ambiguity of the role, understaffed work place, advanced technology, and competition at work. All these add to job stress in nurses $[8,9,25]$.

To examine the effects of COVID-19 on job stress, the mean score of job stress in the target and control groups was examined. The results showed that in addition to poor situation in terms of job stress in the both groups, the mean score of job stress was significantly different between the two groups; so that it was higher in the target group compared to the control group. Therefore, exposure to COVID-19 risk can increase job stress level and create a poor mentalspiritual condition in nurses. This finding is consistent with Husky et al. and Yuanyuan et al. as they showed that job stress in the health team during COVID-19 pandemic was at an undesirable level $[42,43]$. Consistently, Danesh et al. argued that by providing care to COVID-19 patients, nurses experience a frustrating situation that causes notable mental and physical distresses [7].

In addition, the results of studies on contagious diseases epidemics are consistent with the present work. Koh et al. and Wu et al. studied SARS epidemic in nurses and showed that job stress in nurses was not at an acceptable level because of working with SARS patients [44, 45]. One of the reasons for the high job stress level in the target group was failure to employ efficient prevention methods for COVID19 , lack of facial masks and medical equipment, lack of personal protection equipment, lack of N-95 facial masks, and the risk of infection [10, 20, 46]. In addition, the quarantine time period, fear of infection, hopelessness, lack of energy, lack of resources, financial loses, and mortality were other factors in the stress experienced by individuals exposed to COVID19 risk [47-49]. As the results showed, other factors in job stress during the COVID-19 pandemic were staying at home, separation from family, using personal protection equipment for long hours, hearing about others' death due to COVID-19, and posttraumatic stress [50]. Studies have shown that $10-33 \%$ of nurses demonstrated posttraumatic stress symptoms [51, 52]. These symptoms appear after abnormal events in life such as experiencing a severe physical attack, torture, accident, and natural disasters [52]. 
Data analysis indicated an increase in job stress due to the risk of COVID-19 in the control and target groups. The results showed that the mean scores of all elements of job stress were significantly different between the target and control groups $(p<0.05)$ so that the mean score of these elements was higher in the target group. In addition, the maximum and minimum mean scores were obtained by duality of role and physical environment respectively in the both groups. One reason for the higher mean score of role duality can be the lack of clear procedures to fight COVID-19 and ambiguities in nurses' role.

The workload caused by the Covid-19 epidemic can be one of the reasons for the sensible changes in the mean job stress scores between target and control groups.Also, the results of a study conducted by Sawatzky et al. show that high workload is one of the most important sources of stress among nurses [53].

A survey of the results of job stress and demographical information showed that there was a significant relationship in the target group with gender and employment status; so that job stress was higher in women and individuals with temporary work contract. This finding is consistent with Dai et al.'s results about the relationship between job stress and gender during the COVID-19 pandemic in China [54]. Moreover, a study on physicians and nurses of a hospital in Wuhan-China during COVID-19 showed that women in direct contact with COVID-19 patients had a stronger symptoms of stress [55]. This findings can be explained based on vulnerability as it implies that women lack the adaptive resources and approaches to control stressors in their lives [56]. The results about employment status are consistent with Ebadi et al.'s results about depression, stress, and anxiety during the COVID-19 pandemic [57]. The reason for this can be the issue of job security as lack of it is a stressor for nurses [58]. Therefore, it is essential to support nursing community as to job security during the stressful time of COVID-19 pandemic.

The results as to job stress and demographical variables in the control group in general showed that the mean score of job stress in nurses who did not do physical activity was higher than those who had physical activity. This finding is consistent with Mattioli et al. [59], who reported that health improvement behaviors such as physical activity decrease stress and anxiety in individuals.

The results showed that only education level and physical activity, among demographical information were significantly related to the mean score of resilience so that physical activity was significantly related to the mean score of resilience in the both groups. That is, resilience was higher in the participants who had regular physical activity. In addition, the mean score of resilience was significantly different in the participants in terms of education level as those with an M.Sc. degree had a higher resilience than others. These findings are consistent with Afshari et al. Our findings indicated a significant relationship between resilience in the nurses at the risk of COVID-19 infection and education level [23].

This finding is not consistent with Gillespie et al.'s results about the relationship between resilience and education level [60]. One of the explanations for the inconsistent results can be cultural and political differences between the two studies. As shown by the results, resilience in women of the target group was notably less than that of men. This can be due to the less coping capability of women during disasters compared to men. In addition, this finding is explainable given that the mean age of women was higher than men in this study. Studies during the COVID-19 pandemic have shown that psychosocial factors like anxiety, depression, and job stress degrade resilience in individuals [61]. Researchers have maintained that resilience can be an efficient strategy to adapt and create a healthy and stable psychological performance [26]. The findings also showed a strong, significant, and inverse correlation between resilience and job stress. This correlation was stronger in the control group compared to the target group, which can be due to the fact that the factors in job stress can also attenuate resilience in individuals. Therefore, through increasing resilience in nurses at work place, it is possible to lower job stress in them. So that Majumdar et al. recommended proper flexibility policies such as solutions to decrease the risk of COVID-19 infection, which would lead to a higher wellbeing in nurses [62]. In addition, studies have shown that the prevalence of COVID-19 has negatively affected resilience in individuals. Because of this, the mean score of resilience has been declining during the COVID-19 pandemic [23].

Yilmaz et al. studied the effects of resilience as a strategy to face work environment challenges in nurses and showed that by resilience, nurses can adapt better to their work environment and enjoy a healthy and stable psychological performance [26]. Our findings are consistent with Fourur et al. and Lim et al., who showed that an increase in resilience is related to a decrease in job stress [63, 64]. In addition, other studies have shown that to decrease the stress 
caused by COVID-19, useful psychological variable like resilience can improve adaptability in individuals [65]. Resilience is one of the effective variable in lowering the stress and anxiety of COVID-19 [66]. In fact, resilience includes elements like hope and desire to fight and overcome problems; therefore, it can act as an immunity system in the face of crisis like COVID-19 that create considerable stress in the majority of individuals [67]. Based on resilience approach, not all individuals demonstrate negative responses in the face of severe and bitter events and chronic stress [67, 68]. Resilient individuals perceive negative events in a more flexible and realistic way and see them as temporary and limited events [68].

\section{Limitations}

One of the disrupting factors in the study was the effect of stressful conditions outside the work environment, which could have affected job stress level in the participants. Still, this condition was the same for the both study groups, which convinced the authors to omit it. In addition, given the effect of work condition and atmosphere on job stress and resilience, there is a need for further studies in this field before making decisions based on the findings of the present study.

\section{Conclusion}

There was an increase in job stress score and also its elements following the expansion of COVID-19. In addition, there was a significant, strong, and negative correlation between job stress and resilience. The relationship between job stress and resilience and some of demographical variables was also significant. In light of these, the followings are recommended. Providing efficient prevention and treatment methods, improving mental services system, and planning to control demographical factors in job stress like gender, employment status, and physical activity by modifying work schedule, promoting physical activity, and introducing better employment contracts.

\section{Acknowledgments}

The Ethics Committees of the Ahvaz Jundishapur University of Medical Sciences approved the study with ethics number IR.AJUMS.REC.1400.281. Hereby, the authors express their thankful regards to AJUMS.

\section{Conflict of interest}

None of the authors have any conflicts of interest to declare.

\section{References}

[1] Rose VE, Richard ML. Occupational health hazards in hospitals. Prof Saf. 1980;24(12):11-4.

[2] Hitt MA, Miller CC, Colella A. Organizational Behavior: A Strategic Approach. John Wiley \& Sons; 2005. 632 p.

[3] Chen CK, Lin C, Wang SH, Hou TH. A study of job stress, stress coping strategies, and job satisfaction for nurses working in middle-level hospital operating rooms. J Nurs Res. 2009;17(3):199-211.

[4] Chou LP, Li CY, Hu SC. Job stress and burnout in hospital employees: Comparisons of different medical professions in a regional hospital in Taiwan. BMJ Open. 2014;4(2): 1-7.

[5] Nakao M. Work-related stress and psychosomatic medicine. BioPsychoSocial Medicine. 2010;4:1-8.

[6] Gilboa S, Shirom A, Fried Y, Cooper CL. A Meta-Analysis of Work Demand Stressors and Job Performance. In: From Stress to Wellbeing Volume 1. 2013. p. 227-71.

[7] Danesh MK, Garosi E, Golmohamadpour H. The COVID19 Pandemic and nursing challenges: A review of the early literature. Work [Internet]. 2021 May 12;1-14. Available from: https://www.medra.org/servlet/aliasResolver?alias= iospress\&doi=10.3233/WOR-213458

[8] Pinikahana J, Happell B. Stress, burnout and job satisfaction in rural psychiatric nurses: A Victorian study. Aust J Rural Health. 2004;12(3):120-5.

[9] Galdikiene N. Experienced stress among nursing teams in primary health care. 2016;4(1):81-90.

[10] Fernandez R, Lord H, Halcomb E, Moxham L, Middleton $\mathrm{R}$, Alananzeh I, et al. Implications for COVID-19: A systematic review of nurses' experiences of working in acute care hospital settings during a respiratory pandemic. Int J Nurs Stud [Internet]. 2020 Nov;111:103637. Available from: https://linkinghub.elsevier.com/retrieve/pii/ S0020748920301218

[11] Zhang X, Jiang Z, Yuan X, Wang Y, Huang D, Hu R, et al. Nurses reports of actual work hours and preferred work hours per shift among frontline nurses during coronavirus disease 2019 (COVID-19) epidemic: A cross-sectional survey. Int J Nurs Stud. 2020;2019:103635.

[12] Lazarides AL, Belay ES, Anastasio AT, Cook CE, Anakwenze OA. Physician burnout and professional satisfaction in orthopedic surgeons during the COVID-19 Pandemic. Work [Internet]. 2021 May 12;1-8. Available from: https://www.medra.org/servlet/aliasResolver?alias= iospress\&doi=10.3233/WOR-205288

[13] Sohrabi C, Alsafi Z, O'Neill N, Khan M, Kerwan A, Al-Jabir A, et al. World Health Organization declares global emergency: A review of the 2019 novel coronavirus (COVID-19). Int J Surg [Internet]. 2020 Apr;76(February):71-6. Available from: https://linkinghub.elsevier.com/retrieve/pii/ S1743919120301977

[14] Potas N, Koçtürk N, Toygar SA. Anxiety effects on quality of life during the COVID-19 outbreak: A parallel-serial mediation model among nurses in Turkey. Work [Internet]. 2021 May 12;1-9. Available from: https://www.medra.org/ 
servlet/aliasResolver?alias=iospress \&doi=10.3233/WOR205050

[15] Wang C, Horby PW, Hayden FG, Gao GF. A novel coronavirus outbreak of global health concern. Lancet [Internet]. 2020;395(10223):470-3. Available from: https://linking hub.elsevier.com/retrieve/pii/S0140673620301859

[16] Hawryluck L, Gold WL, Robinson S, Pogorski S, Galea S, Styra R. SARS Control and Psychological Effects of Quarantine,. Emerg Infect Dis. 2004;10(7):1206.

[17] Pniak B, Leszczak J, Adamczyk M, Rusek W, Matłosz P, Guzik A. Occupational burnout among active physiotherapists working in clinical hospitals during the COVID-19 pandemic in south-eastern Poland. Work [Internet]. 2021; 68(2):285-95. Available from: https://www.medra.org/se rvlet/aliasResolver?alias=iospress $\&$ doi $=10.3233 /$ WOR203375

[18] Mounesan L, Eybpoosh S, Haghdoost A, Moradi G, Mostafavi E. Is reporting many cases of COVID-19 in Iran due to strength or weakness of Iran's health system? Iran J Microbiol [Internet]. 2020;12(2):73-6. Available from: http://www.ncbi.nlm.nih.gov/pubmed/32494340

[19] Maben J, Bridges J. Covid-19: Supporting nurses' psychological and mental health. J Clin Nurs [Internet]. 2020; 29(15-16):2742-50. Available from: https://onlinelibrary. wiley.com/doi/10.1111/jocn.15307

[20] Arnout BA, Al-dabbagh ZS, Eid NA Al, Eid MA Al. The Effects of Corona Virus (COVID-19) Outbreak on the Individuals 'Mental Health and on the Decision Makers : A Comparative Epidemiological Study The Effects of Corona Virus (COVID-19) Outbreak on the Individuals ' Mental Health and on the Decision. Heal Sci. 2020;9(3):26-47.

[21] Majumdar P, Biswas A, Sahu S. COVID-19 pandemic and lockdown: cause of sleep disruption, depression, somatic pain, and increased screen exposure of office workers and students of India. Chronobiol Int [Internet]. 20202;37(8): 1191-200. Available from: https://www.tandfonline.com/ doi/full/10.1080/07420528.2020.1786107

[22] Liu CY, Yang YZ, Zhang XM, Xu X, Dou QL, Zhang WW, et al. The prevalence and influencing factors in anxiety in medical workers fighting COVID-19 in China: A cross-sectional survey. Epidemiol Infect. 2020;148(4):1-17.

[23] Afshari D, Nourollahi-darabad M, Chinisaz N. Demographic predictors of resilience among nurses during the COVID-19 pandemic. Work [Internet]. 2021;68(2): 297-303. Available from: https://www.medra.org/servlet/ aliasResolver?alias=iospress\&doi=10.3233/WOR-203376

[24] Allan JL, Farquharson B, Johnston DW, Jones MC, Choudhary CJ JM. Stress in telephone helpline nurses is associated with failures of concentration, attention and memory, and with more conservative referral decisions. Br J Psychol. 2014;105(2):200-13.

[25] Chesak SS, Bhagra A, Schroeder DR, Foy DA, Cutshall SM, Sood A. Enhancing resilience among new nurses: Feasibility and efficacy of a pilot intervention. Ochsner J. 2015; 15(1):38-44.

[26] Yılmaz EB. Resilience as a strategy for struggling against challenges related to the nursing profession. Chinese Nurs Res. 2017;4(1):9-13.

[27] Shirali GA, Azadian S, Saki A. A new framework for assessing hospital crisis management based on resilience engineering approach. Work [Internet]. 2016;54(2):43544. Available from: https://www.medra.org/servlet/alias Resolver?alias=iospress\&doi=10.3233/WOR-162329

[28] Woods DD, Hollnagel E. Joint Cognitive Systems. Joint Cognitive Systems. CRC/Taylor \& Francis; 2006. 219 p.
[29] Azadeh A, Process PA-J of LP in the, 2014 U. The impact of job security, satisfaction and stress on performance assessment and optimization of generation companies. J Loss Prev Process Ind. 2014;32:343-8.

[30] Woods DD. Escaping failures of foresight. Saf Sci. 2009; 47(4):498-501.

[31] Lanz JJ. Examining the Impact of Resilience on Work Stress and Strains in Nurses. Diss Abstr Int Sect B Sci Eng. 2015; 77(6-B(E)):No-Specified.

[32] Cross W. Building Resilience in Nurses: The Need for a Multiple Pronged Approach. J Nurs Care. 2015;04(02): $10-1$.

[33] Singh S, Sharma T. Affect of Adversity Quotient on the Occupational Stress of IT Managers in India. Procedia Comput Sci. 2017;122:86-93.

[34] Shirali G, Afshari D, amiri arman, kiani sima, rashnoudi payam. The Impact of Job Stress on the Productivity of workers of Southwest Oil and Gas Company in Iran. J Occup Hyg Eng. 2019;6(3):46-52.

[35] Mehrinejad SA, Tarsafi M, Rajabimoghadam S. Predictability of Students' Resiliency by Their Spirituality. Procedia Soc Behav Sci. 2015;205(May):396-400.

[36] Khodabakhshi Koolaee A, Heidari S, Khoshkonesh A, Heidari M. Relationship between spiritual intelligence and resilience to stress in preference of delivery method in pregnant women. Iran J Obstet Gynecol Infertil [Internet]. 2013; 16(58):8-15. Available from: http://eprints.mums.ac.ir/id/ eprint $/ 4765$

[37] Sharifian SA, Aminian O, Kiyani M, Barouni S, Amiri F. the evaluation of the degree of occupational stress and factors influencing it in forensic physicians working in legal medicine organization in tehran - autumn of 2005. Sci J FORENSIC Med. 200AD;12(3):144e50.

[38] Hoboubi N, Choobineh A, Kamari Ghanavati F, Keshavarzi S, Akbar Hosseini A. The Impact of Job Stress and Job Satisfaction on Workforce Productivity in an Iranian Petrochemical Industry. Saf Health Work. 2017;8(1): 67-71.

[39] Saadattalab A, Jafari M. Mediator Role of spiritual happiness in the relationship between social capital and social support with resiliency in employees against, Covid-19 diseases epidemic in the period of Social distance. J Res Psychol Heal. 2020;14(1):115-29.

[40] Almazan JU, Albougami AS, Alamri MS. Exploring nurses' work-related stress in an acute care hospital in KSA. J Taibah Univ Med Sci. 2019;14(4):376-82.

[41] Kokoroko E, Sanda MA. Effect of Workload on Job Stress of Ghanaian OPD Nurses: The Role of Coworker Support. Saf Health Work. 2019;10(3):341-6.

[42] Husky MM, Kovess-Masfety V SJ. Stress and anxiety among university students in France during Covid-19 mandatory confinement. Compr Psychiatry. 2020;1(102): 152191.

[43] Mo Y, Deng L, Zhang L, Lang Q, Liao C, Wang N, et al. Work stress among Chinese nurses to support Wuhan in fighting against COVID-19 epidemic. J Nurs Manag. 2020; 28(5):1002-9.

[44] Can W, Learn W, Koh D, Lim MK, Chia SE, Ko SM. Risk perception and impact of Severe Acute Respiratory Syndrome (SARS) on work and personal Lives of. Med Care. 2005;43(7):676-82.

[45] Poon E, Liu KS, Cheong DL, Lee CK, Yam LYC, Tang WN. Impact of severe acute respiratory syndrome on anxiety levels of frontline health care workers. Hong Kong Med J. 2004;10(5):325-30. 
[46] Lau JTF, Yang X, Tsui HY, Kim JH. Impacts of SARS on health-seeking behaviors in general population in Hong Kong. Prev Med (Baltim). 2005;41(2):454-62.

[47] Kawana N, Ishimatsu SI, Kanda K. Psycho-physiological effects of the terrorist sarin attack on the Tokyo subway system. Mil Med. 2001;166(12 SUPPL.):23-6.

[48] Cardenas J, Williams K, Wilson JP, Fanouraki G, Singh A. PSTD, major depressive symptoms, and substance abuse following September 11, 2001, in a midwestern university population. Int J Emerg Ment Health. 2003;5(1):15-28.

[49] Galea S, Resnick H, Ahern J, Gold J, Bucuvalas M, Kilpatrick D, et al. Posttraumatic stress disorder in Manhattan, New York City, after the September 11th terrorist attacks. J Urban Heal. 2002;79(3):340-53.

[50] Brown S, Doom J, Lechuga-Peña S, Watamura S, Koppels T. Stress and parenting during the global COVID-19 pandemic. Child Abuse Negl. 2020;1(2):110:104699.

[51] Wu P, Liu X, Fang Y, Fan B, Fuller CJ, Guan Z, Yao Z, Kong J, Lu J LI. Alcohol abuse/dependence symptoms among hospital employees exposed to a SARS outbreak. Alcohol Alcohol. 2008;1(43):706-12.

[52] Su TP, Lien TC, Yang CY, Su YL, Wang JH, Tsai SL YJ. Prevalence of psychiatric morbidity and psychological adaptation of the nurses in a structured SARS caring unit during outbreak: a prospective and periodic assessment study in Taiwan. J Psychiatr Res. 2007;1(41):119-30.

[53] Sawatzky J-A V. Stress in critical care nurses: Actual and perceived. Hear Lung [Internet]. 1996;25(5):409-17. Available from: https://linkinghub.elsevier.com/retrieve/pii/ S0147956396800847

[54] Dai Y, Hu G, Xiong H, Qiu H YX. Psychological impact of the coronavirus disease 2019 (COVID-19) outbreak on healthcare workers in China. MedRxiv. 2020;

[55] Lai J, Ma S, Wang Y, Cai Z, Hu J, Wei N, et al. Factors Associated With Mental Health Outcomes Among Health Care Workers Exposed to Coronavirus Disease 2019. JAMA Netw open. 2020;3(3):e203976.

[56] Thoits PA. Gender differences in coping with emotional distress. In: The social context of coping. 1st ed. Springer; 1919. p. 107-38.

[57] Abadi T, Askari M, Miri K, Nia M. Depression, stress and anxiety of nurses in COVID-19 pandemic in Nohe-Dey Hospital in Torbat-e-Heydariyeh city, Iran. J Mil Med. 2020; 22(6):526-33.
[58] Caplan RD, Jones KW. Effects of work load, role ambiguity, and type A personality on anxiety, depression, and heart rate. J Appl Psychol. 1975;60(6):713.

[59] Mattioli A, Ballerini Puviani M. Lifestyle at time of COVID19: How could quarantine affect cardiovascular risk. Am J Lifestyle Med. 2020;14(3):240-2.

[60] Gillespie BM, Chaboyer W, Wallis M, Grimbeek P. Resilience in the operating room: developing and testing of a resilience model. J Adv Nurs [Internet]. 2007 Aug [cited 2019 Jun 19];59(4):427-38. Available from: http:// doi.wiley.com/10.1111/j.1365-2648.2007.04340.x

[61] Barzilay R, Moore TM, Greenberg DM, DiDomenico GE, Brown LA, White LK, Gur RC GR. Resilience, COVID-19related stress, anxiety and depression during the pandemic in a large population enriched for healthcare providers. Transl Psychiatry. 2020;10(1):1-8.

[62] Majumdar P, Barman O, Chakraborty P, Sahu S. COVID-19 Pandemic and Rotational Shift Work: Impact on Physical and Mental Health of Indian Nurses. Int J Res. 2020;6(2): 60-72.

[63] Foureur M, Besley K, Burton G, Yu N, Crisp J. Enhancing the resilience of nurses and midwives: Pilot of a mindfulnessbased program for increased health, sense of coherence and decreased depression, anxiety and stress. Contemp Nurse. 2013;45(1):114-25.

[64] Lim J, Bogossian F, Ahern K. Stress and coping in Singaporean nurses: A literature review. Nurs Heal Sci. 2010; 12(2):251-8.

[65] Polizzi C, Lynn SJ, Perry A. Stress and Coping in the Time of COVID-19: Pathways to Resilience and Recovery Craig Polizzi, Steven Jay Lynn, Andrew Perry. Clin Neuropsychiatry. 2020;17(2):59-62.

[66] Lupe SE, Keefer L, Szigethy E. Gaining resilience and reducing stress in the age of COVID-19. Curr Opin Gastroenterol. 2020;36(4):295-303.

[67] Philips KH, Brintz CE, Moss K, Gaylord SA. Didgeridoo Sound Meditation for Stress Reduction and Mood Enhancement in Undergraduates: A Randomized Controlled Trial. Glob Adv Heal Med. 2019;8(1):216495611987936.

[68] Bester G, Kuyper N. The Influence of Additional Educational Support on Poverty-Stricken Adolescents' Resilience and Academic Performance. Africa Educ Rev. 2020;17(3): 158-74. 